\title{
Psychosocial Challenges Faced by Female Health Care Professionals During the COVID-19 Outbreak in Lahore, Pakistan: A Qualitative Study
}

\section{Sumbal Shahbaz}

University of the Punjab

Muhammad Zeshan Ashraf

University of the Punjab

Rubeena Zakar

University of the Punjab

Florian Fischer ( $\square$ florian.fischer1@charite.de)

Charite Universitatsmedizin Berlin https://orcid.org/0000-0002-4388-1245

Research article

Keywords: coronavirus, SARS-CoV-2, women, practitioner, physician, working environment

Posted Date: December 3rd, 2020

DOI: https://doi.org/10.21203/rs.3.rs-116788/v1

License: (c) (i) This work is licensed under a Creative Commons Attribution 4.0 International License.

Read Full License 


\section{Abstract}

Background: The novel coronavirus disease (COVID-19) is disseminating rapidly, increasing stress and challenges for health care professionals around the world. This study aims to discover the psychosocial challenges faced by female health care professionals (HCPs) treating COVID-19 patients in Pakistan.

Methods: Using an empirical phenomenological methodology, semi-structured telephone-based qualitative interviews were taken from 22 female HCPs who were providing their expertise for COVID-19 patients in tertiary level hospitals of Lahore, Pakistan. Purposive sampling has been used for recruitment. The interviews were taken from July 20 to August 20, 2020. The interviews were analysed using thematic analysis.

Results: This study discovered the psychosocial challenges faced by female HCPs serving COVID-19 patients. Five themes have been observed in the interviews: psychological concerns of HCPs while treating COVID-19 patients; feelings towards COVID-19 patients; confidence in government, administration and self-reflection; challenges as female HCPs and coping strategies; and finally, future concerns and recommendations. Many of these themes have also been linked with cultural issues, making the results specific for Pakistan.

Conclusions: During the COVID-19 pandemic, female front-line HCPs have faced immense psychosocial pressure, starting from unsupportive family norms to unwelcoming working environment and insensitive hospital administration. Moreover, rumours among general public, lack of proper training, missing incentives and improper system surveillance had increased the anxiety and stress among HCPs. Hence, legislators are advised to take appropriate actions countrywide in order to improve the still on-going challenges and to support female HCPs in their working environment.

\section{Background}

The novel coronavirus (COVID-19) has spread very quickly around the globe. The pandemic has led to acute cases of infections, but is also associated with adverse long-term health consequences. In several countries, it has almost led to a collapse of the health care system, including Pakistan [1, 2]. This highly contagious virus imposing an enormous scale of infection, enforced massive pressure on governments, medical institutions and health care professionals (HCPs) [3, 4]. Like other coronaviruses, i.e. SARS and MERS, inter-human spread of COVID-19 is typically transmitted via aerosols. Thus, the COVID-19 pandemic is undoubtedly the largest outbreak of atypical pneumonia after the SARS outbreak in 2003 with the number of cases unrelentingly escalating beyond geographical restrictions [5].

Pakistan is surrounded by highly affected countries like China, being the first one to experience this outbreak, and Iran [6]. According to data from the John Hopkins University, the highest numbers of incident cases and deaths due to COVID-19 in Pakistan have been observed in June 2020 [7], the month before this study has been conducted. Within the province of Punjab, the city of Lahore has been the epicentre with the highest number of confirmed cases. Therefore, the government has introduced 
recommendations of social distancing and ordered lockdowns (e.g. closing of all educational institutions) already in March 2020 [8]. This is associated with psychological stress for the general population and the health care system in particular [9]. To reinforce emergency preparedness on national and community level, the government of Pakistan summoned orders for shutting down outpatient treatment as well as elective surgical facilities [10]. However, qualified HCPs are essential in such a situation. Their wellbeing and safety are vital for relentless and advanced patient care, in addition to combating the outbreak [11].

In Pakistan, females are an indispensable part of the health care system as more than $50 \%$ of all HCPs are females serving as doctors, nurses and allied health professionals in all corona-dedicated hospitals within the country [12]. On the one hand, female HCPs have sacrificed their own necessities to contribute in combating the pandemic and have shown highest levels of professional obligation. On the other hand, they have faced emotional and psychological stress as well as social isolation and abandonment because of the health threats [13]. Globally, studies have revealed that frontline HCPs handling COVID-19 patients are exposed to greater risks of psychological health issues, like anxiety, hopelessness, insomnia, and tension $[8,10]$. However, no qualitative study regarding the psychosocial challenges faced by female HCPs serving COVID-19 patients in Pakistan has been published yet. For that reason, this qualitative study aims to describe the experiences and challenges which the physicians, nurses and allied health professionals caring for COVID-19 patients were faced with personally and professionally during the outbreak.

\section{Methods}

\section{Study design and participants}

We applied a qualitative empirical phenomenological methodology [14] to analyse the psychosocial challenges faced by female HCPs treating COVID-19 patients in Pakistan. This scientific approach emphases on the feelings and practises of participants and gives an inside perspective of challenges they had to face. We focussed on HCPs who just had basic infectious disease management training during their medical education, but no practical experience in infectious disease management before the pandemic. We included study participants who directly treated COVID-19 patients in Lahore, i.e. Services hospital and Mayo hospital. Using purposive sampling, 22 female HCPs, including doctors, nurses, and allied health professionals were selected. We recruited participants until a data saturation point has been reached.

\section{Data collection and analysis}

Data was collected through telephonic in-depth interviews (IDI) with study participants [15] to maintain social distancing. Prior to the interview, time was fixed with participants and study objectives were explained. Anonymity and confidentiality of the study participants were ensured. Verbal informed consent was taken before the start of each interview. Voice recording was done with respondent's permission. 
We used a semi-structured interview guide for data collection (Additional file 1), which has been developed for this study. This guide started with general questions related to participant's age, marital status, number of children, and the duration of duty in COVID-19 wards. Afterwards, comprehensive openended questions were used to get insider perspectives on questions like: "How does taking care of COVID19 patients differ from routine patients?", "What are your core psychological concerns about treating COVID-19 patients?", "What kind of training did you receive before treating COVID-19 patients?", and "What challenges did you encounter and what were your coping methods?". For getting a better picture about the challenges related to psychosocial aspects, we used the following questions: "How did you manage your work and family life during the pandemic?", "In which way did you receive support from your family?", "Which societal pressures have you been faced with?", "Have you or any of your family members be infected", "Who helped you in repetitive quarantine periods?", and "Did you receive any stress releasing therapy or assessment?". Probing questions (such as "Please elaborate..." or "Please explain...") have also been used. Each interview took about 30 to 40 minutes. Each interview was immediately transcribed after its conduction.

The analysis was done according to qualitative phenomenological techniques. The transcripts were read several times to identify themes and sub-themes. At that point, all material was reviewed and summarized according to the outlined themes by two coders. Thematic analysis was done for drawing conclusions.

Ethical approval was obtained from ethical review board of the Department of Public Health, University of the Punjab, Lahore.

\section{Results}

The study sample comprised of 22 female HCPs, out of which 9 (40.9\%) were doctors, 8 (36.4\%) were nurses, and $5(22.7 \%)$ were allied health professionals. Their age ranged from 25 to 35 years. According to data collected, 14 of the participants were married, 11 of them having children. All of these were living with their families. From the remaining 8 participants who were unmarried, 5 used to live in a nursing/doctor's hostel. This study explored the psychosocial challenges and lived experiences of HCPs serving COVID-19 patients using thematic analysis. Their interviews outlined the following five common themes among the entire study participants: psychological concerns of HCPs while treating COVID-19 patients; feelings towards COVID-19 patients; confidence in government, administration and selfreflection; challenges as female HCPs and coping strategies; and finally, future concerns and recommendations. Many of these themes have also been linked with cultural issues, making the results specific for Pakistan.

\section{Psychological concerns of HCPs while treating COVID-19 patients}

All of the study participants were concerned about the contagiousness of the virus, not just for themselves but also for people around them. The aggressive behaviour of the virus, unanticipated deaths, even of very young physicians, made them feel that they are into a crisis and will not be able to cope with 
it. Most of the married participants were more concerned about their children and parents, because treating COVID-19 patients could have made them to carriers of the virus. Another fear for some of the study participants $(n=7)$ was post-duty quarantine. This is exemplified by a statement of one participant:

"Working with COVID-19 patients in intensive care units was more like working in a morgue. You can feel death everywhere. Somehow you manage to work during duty hours, but when you are alone it's hard to collect your broken pieces. You have no shoulder to cry and no one to boost you."

This feeling made quarantine even harder than the duty itself. Some respondents claimed about having difficulties in arranging help to take care of their necessities (related to food, supplies etc.) during postduty quarantine while other complained about lack of emotional and social support for female HCPs. Those whose partners had a non-medical profession left them alone (during COVID-19 duties), not only physically but also emotionally. The respondents mentioned that their partners had the feeling that the HCPs preferred the job over their health and safety. Some respondents who did not had children preferred themselves to stay away from home during COVID-19 duties, because they were afraid of getting blamed for being carriers at in-laws' home. Those who had partners in the same professions reported to have more emotional support. However, they had no quarantine period during or after COVID-19 duties. They were living with their families all the time with additional household chores. Only unmarried participants had full support from their families and maintained in the recommended quarantine during and after their duty. The entire study participants acknowledged that their parents and siblings were a constant support for them.

Initially, social support was provided from the general public, but it deteriorated over time due to fake rumours about COVID-19 deaths. One of the participants confessed that people even asked her about how much money she gets for every death. One other claimed:

"People got aggressive in later stages when we advised them to go for COVID-19 testing and assumed that we are planning to kill their patients."

Some participants claimed that people with educated relatives and people around them got appreciation for their efforts while combating the pandemic. On the contrary, others received a negative gush all the time. All the participants concluded that the social circumstances were better initially, when people were afraid of this pandemic. However, later on the number of cases and deaths increased, whereas fear, care and social distancing decreased due to negative rumours and circulating tales about COVID-19 deaths. This has been enforced through social media which not only increased work pressure but also stress and health concerns.

\section{Feelings towards COVID-19 patients}

All HCPs felt depressed while treating COVID-19 patients due to the frequently unexpected response of the virus and different than usual treatment guidelines. One of the study participants reported: 
"We were told not to resuscitate and not to ventilate patients in intensive care unit. That was quite frustrating for me as I always got a feeling that it is injustice to the patient."

Another participant told:

"I once resuscitated a young patient in intensive care unit and he gave positive response. I was so happy, but my fellow colleagues gave quite a backlash instead of appreciating me that why I would endanger myself for this patient and that I am setting a wrong trend."

Another respondent explained:

"Despite of my experience I had no idea how this virus would work with anybody. In a moment patients FiO2 [Fraction of inspired oxygen] was improving, next moment he was gone which was really depressing - being a competent doctor."

Another study participant claimed counselling attendants as the most difficult task for female HCPs, as they were not allowed to see their patients. The speed with which the disease progresses in few people made their attendants feel that the patient has been fine and the hospital staff killed him, which made them misbehave with the health care personnel. This is exemplified by the following statement.

"If you were treating a patient from last 12 hours which is getting better during your shift, and 2 hours after shift change you get to know he died, you get a feeling that he was being mistreated. Maybe you could have changed this if you had stayed longer. In reality, things would have remained the same, but you keep on blaming yourself and others."

Some HCPs claimed that lower rate of survival among intensive care unit's patients was due to carelessness of senior consultants. One study participant told:

"We were only supposed to follow instructions given during rounds, but were not allowed to make decisions for patients. In case of emergency we had to call ghostly present seniors and by the time senior would arrive the patient has died."

Some of the HCPs claimed lack of psychological support made patients more anxious and they developed shortness of breath due to overwhelming depression caused by COVID-19 and loneliness. On the contrary, others referred to a lack of ambient temperature in COVID-19 wards and intensive care units along with hot and humid weather as a reason for shortness of breath.

Few study participants claimed power inequality at its peak during the coronavirus pandemic:

"Relatives of powerful people got to stay in intensive care units, even if they don't need it or have their beds booked for emergency situations, whereas deserving ones suffered."

Another one told: 
"Due to shortage of nursing staff - sometimes one nurse per ten beds - patients who had influential doctor kids or siblings stayed in intensive care units with them - wearing proper protective gears - and provided nursing care to their patients themselves around the clock. This had a very positive effect on recovery of their patients, whereas those having no links were not allowed to even see their patients from outside the ward."

One participant also complained about the lack of portable equipment like dialysis machines and echocardiography for COVID-19 patients which increased the preventable death toll. All participants had multiple concerns regarding treating COVID-19 patients which demoted their stamina and courage to work in difficult times.

\section{Confidence in government, administration and self-reflection}

All participants revealed their cynicism for health departments due to a lack of training facilities for dealing with COVID-19 patients. The only training held by authorities was during March 2020, in form of a session involving few senior specialists from each department. A respondent explained:

"The training session was very general. It was not COVID-19 oriented or COVID-19 specific at all."

Another participant further elaborated:

"The training included those seniors who never bothered to serve COVID-19 patient nor explained it to other members of the department."

One HCP who took an up-to-date training session while working in a reputable private hospital in early days of the corona pandemic told:

"All the staff of the government facility, including medical and paramedical, had no idea about the right way of donning and doffing personal protective equipment, which lead to increased corona positive cases among them."

Most of the participants had a positive attitude towards efforts the government put in combating the pandemic. However, all of them were very disappointed with the hospital administrations which failed in providing quality treatment facilities. There has been a lack of facilities for HCPs who got COVID-19 positive while treating patients. This is illustrated by the following statements:

"There wasn't even any separate testing area for HCPs. They had to use links to get a bed in hospital if they get sick."

"If an HCP is tested positive while working in a COVID-19 ward, he gets 15 days quarantine period. But if he gets positive after it, administration refused to give rest, deducted pays even after providing COVID-19 reports and gave them extra duties after returning to work." 
All of the respondents claimed that they got no additional health allowance even after several announcements from government:

"My colleague got COVID-19 positive while serving patients. Her family opted for a private facility when she needed intensive care, but the government offered no health allowance."

"Due to public announcements of salary incentives by the government, the general public had an impression that doctors are getting a lot of reward for their services, whereas in real not a single one of us got a single rupee incentive."

All study participants demanded check and balance from government about ground realities going on in hospitals. A respondent explained:

"Seniors and influential people of departments just came, made photographs and took credit while those juniors who actually worked did not get any gratitude or acceptance from administration. This increased their depression and decreased their motivation to work."

Another one added:

"There must be check and balance at every level so that who worked get credit for their hard work, and those who didn't get motivated to work next time. But the situation is vice versa here."

Furthermore, the issue of pregnancies among HCPs has been addressed by the study participants:

"Besides government policies of not putting pregnant ladies and staff with comorbidities on COVID-19 duties, hospital administration forced them to do duties and threatens them to terminate if they refused."

"Besides being pregnant I was forced to do duty in COVID-19 intensive care units. And when I turned COVID-19 positive, the administration refused to give quarantine as I had mild symptoms. I kept on working all the time while being COVID-19 positive."

More than $70 \%$ of the study participants claimed that this epidemic increased their confidence in themselves and their competence. Most of them conveyed that even though the pandemic prevention duty was hard, it triggered a process of introspection and self-analysis. Therefore, it strengthened their determination, revealed their true potential, and augmented their motivational spirits.

\section{Challenges as female HCPs and coping strategies}

Almost all study participants faced additional challenges related to being a female HCP. The majority have faced major transportation challenges due to lockdowns and unavailability of public and private transport. For that reason, they needed additional family tantrums by daily requesting their spouses to drop them, because of missing driving licenses among women. All the participants with children had additional challenges of maintaining family chores along with COVID-19 duties. For example, housemaids were not permitted to work at their homes owing to fear of transmitting the virus through 
them, as most of the maids work in multiple houses. Moreover, home-schooling and online classes of children without any help increased their conflicts related to work-family-balance during COVID-19 duties. One participant explained her concerns in the following way:

"My child is just eight months old and it was impossible for me to stay away from him as I had nobody to look after him."

Another one claimed:

"Nobody in my family was ready to take responsibility of my three kids. So, I had to be with them."

The challenge of families getting infected is highlighted by a further HCP:

"My whole family got COVID-19 positive due to my repetitive duties with COVID-19 patients and staying with them without being quarantined."

For most of the married participants, the spouse refused to take family responsibility alone. However, the situation was also tough for unmarried hostel residing staff, because during their post duty quarantine period or if turned COVID-19 positive they were ordered to leave hospital's hostels. The study participants mentioned that male HCPs can stay in hotels or private facilities for quarantine, but female HCPs cannot do so. Instead of showing gratitude and support during these difficult times, they were thrown out of hostels by the administration; and by moving to their residence in other cities they became a carrier for others as well.

Another problem faced by the participants was a lack of changing rooms for females. According to cultural norms, 14 participants used to wear hijab or dupatta, which are scarfs that some Muslim women wear to cover their hair and neck. But after removing the personal protective equipment, they had to go without wearing such a kind of a scarf which was quite uncomfortable for them. In one facility, even a washroom was not available where they could go before leaving the hospital. All married respondents told that they had extra burden of home-schooling children in addition to basic household works which were previously done by maids.

Another serious challenge highlighted by female HCPs was inadequate security in hospitals. Especially those who worked at night shift were badly handled by attendants of deceased patients and hospital security failed to provide safety. On participant explained:

"I hide whole night in a nearby ward as attendants of patients were beating all the staff when we broke the news of their patient's expiry."

Another one told:

"Due to negativity spread in the general public at later stage, one night few attendants broke the door of the intensive care unit and we ran to save our lives. Hospital security failed to give protection, so finally we called police who saved us." 
These circumstances increased fear and anxiety among HCPs, but not a single one of the study participants tried any psychological counselling or assessment as stress coping strategy. All of the participants increased praying and tried to make their bond strong with Allah as meditation. The majority of female HCPs also felt better after crying a lot alone when they were tired of battling with this situation. Moreover, health authorities also took no notice about mental health of HCPs and there was no workshop or sessions about psychological coping of the ongoing pandemic crises. This has been judged as an ignorant and irresponsible act by the interviewees.

\section{Future concerns and recommendations}

Almost all of the study participants claimed that the pandemic made them realise the importance of living "today". This is illustrated by the following statements:

"We never get grateful for what we have and keep on planning for a better future. This pandemic made us realise the importance of health, family and self-care."

"This pandemic made our belief strong in the supremacy of God almighty as a lot of professionals had their plans to immigrate, to go for vacations. But they had to surrender in front of God's will."

All respondents agreed that there must be a disaster plan in case of a second wave of COVID-19. The participants emphasized:

"Response should be fast, special recruitments for corona came after the peak months of epidemic due to which they suffered additional load."

"Protective gears were rare during the initial days. And fear was at its peak which created a lot of pressure on health care professionals. Therefore, government should keep it now for any emergency situation in the future."

Almost all of study participant suggested that the government should reward those who worked during the pandemic. This relates not only to financial issues, but also a way of appreciation which would increase their courage and dedication towards work.

Moreover, improving the ratio between patients and HCPs and appropriate guidelines and recommendation to handle epidemics must be a regular part of medical training. A participant highlighted this issue in the following manner:

"The drill to work as a team should be improved. We know how to work as a team in our respective departments, but working collectively as a team with different departments must be learned and improved."

Despite tough circumstances and challenges, 13 of the 22 respondents (59.1\%) felt happy to serve during the COVID-19 pandemic. Firstly, they got a feeling that they fulfilled the oath they took to serve the mankind. Secondly, their self-confidence got a huge boost due to working in such difficult times. 


\section{Discussion}

In the light of any health emergency, HCPs are always at the forefront, putting up their lives for the health of the community. However, this study discovered psychosocial challenges faced by female HCPs during COVID-19, which are at least partly specific regarding cultural issues in Pakistan. Caring for patients with COVID-19 led to mental and social discomfort for female HCPs. Whereas in other developed countries intense working conditions, enormous load of patients, and shortage of protective gears was the main source of anxiety $[5,13]$, our study highlight that apprehensions about family were enhanced due to lack of support. Furthermore, difficulties at the hospital administration level led to further challenges resulting in psychosocial stress.

Physical fatigue, psychological vulnerability, (perceived) health risks for the family, lack of adequate training, equipment and facilities in addition to lack of support from society led to undesirable emotions, such as anxiety, distress, and helplessness, which have already been described in previous studies [16, 17]. This study shows that HCPs - no matter whether physicians, nurses or allied professionals - had significantly higher negative sentiments about personal health directly after the pandemic started.

Therefore, timely psychological intervention is needed for HCPs in any epidemic. Moreover, it is important to provide facilities during and post duty quarantine for female HCPs to avoid becoming carriers for their families and communities. Study results revealed that after working with COVID-19 patients and not being quarantined due to family and societal responsibilities, exposed female HCPs to extreme frustration, fear of transmitting the virus, and clash among the commitment to family and occupation. In addition, by not being provided with any safe quarantining facilities for employees, health insurances/incentives and safe working environments, feelings of resentment and disappointment were seen among all the HCPs.

The study highlighted the immediate need to start appropriate pandemic combating training sessions for all HCPs at every level to improve patient's and HCP's health. Furthermore, it emphasized the need for improving health policies to provide immediate facilities as well as check and balance to promote and acknowledge those who worked hard instead of those who have personal links with hospital administrations. Moreover, comorbid and pregnant HCPs should be given serious concern to decrease their risks of infection. At the same time, adequate infant and child care facilities should be provided.

However, during the present circumstances the participants felt distressed and self-accused of infecting their families [18]. The inside perspective of these HCPs described the need for direct communication between government and care providing HCPs. The current study also indicated the constant need of informing people about the actual situation during the pandemic and rectification of local rumours which create a negative impression of already suffering and struggling HCPs [19].

In addition, numerous studies have revealed that outbreaks are a cause of psychological distress for care providers [20]. Therefore, a proper system for psychological evaluation must be developed. Positive coping styles in combination with social support must be mediated for releasing stress. Self-reflecting techniques need to be promoted to boost professional identity [21]. Moreover, enthusiastically guiding 
and motivating HCPs need a place and time for promoting psychological growth and positive psychological adjustment [13].

Various studies guide us that proper health facilities and health allowances for HCPs would improve their trust level in authorities as well as their willingness to work in such difficult times [22, 23]. Testing and treatment of HCPs along with their family members should be offered without discrimination [24]. Hence safety of HCPs should be prioritized, by up to date training, health education, adequate duty and quarantine times, health incentives and insurances, availability of protective gears, and psychological provision, must be a priority to facilitate female HCPs [25].

\section{Limitations}

Limitations of the study are mainly related to the purposive sampling. This study does not aim at representativity, but it provided valuable insights into the experiences of female HCPs. Due to the extremely contagious nature of the coronavirus and to prevent cross-infection, we were not able to conduct focus group discussions, which would have opened further valuable possibilities to explore. Several results are closely associated with cultural factors. For that reason, the study is specific for the Pakistani context. However, it would be advisable for future research to include these cultural aspects for understanding the challenges and responses towards COVID-19 in a better way.

\section{Conclusions}

This research provided an inside perspective of psychosocial challenges faced by HCPs in Pakistan during COVID-19. The results found that HCPs are psychosocially challenged through society and hospital authorities. Not only female HCPs, but also their families and the community are at stake due to inadequate post duty quarantine techniques and facilities. Psychological and financial support in addition to health insurance a should be offered to female HCPs from governmental and nongovernmental institutions. Therefore, health policy reforms in case of any other health emergency in the future are needed to maintain HCP's family's stability as well as their willingness and ability to work.

\section{List Of Abbreviations}

COVID-19 Coronavirus disease 2019

HCP Health care professional

\section{Declarations}

\section{Ethical Approval and Consent to Participate}

We received an ethical approval for this study from the Ethical Review Board of the Department of Public Health, University of the Punjab, Lahore. Anonymity and confidentiality of participants was maintained 
and verbal informed consent was taken. Consent was verbal because interviews have been conducted via telephone. According to recommendations by ethical review board and data protection officer, verbal informed consent has been documented at each interview guide prior to the interview.

\section{Consent for Publication}

Not applicable.

\section{Availability of Data and Materials}

Data is available from corresponding author upon reasonable request.

\section{Competing Interest}

The authors declare that no competing interest exist. FF serves on the Editorial Board of BMC Women's Health as Associate Editor.

\section{Funding}

This research received no supporting funds from any funding agency in the public, commercial, or not-forprofit sector.

\section{Authors Contributions}

The study was conceptualized by SS, MZA and RZ. SS and MZA conducted data collection. SS, MZA, RZ and FF analysed the data. SS drafted the manuscript, MZA, RZ and FF revised it critically for important intellectual content. All authors reviewed the final version of the manuscript.

\section{Acknowledgements}

We acknowledge support from the German Research Foundation (DFG) and the Open Access Publication Fund of Charité - Universitätsmedizin Berlin.

\section{References}

1. Sahin AR, Erdogan A, Agaoglu PM, Dineri Y, Cakirci AY, Senel ME, Okyay RA, Tasdogan AM. 2019 novel coronavirus (COVID-19) outbreak: a review of the current literature. EJMO. 2020;4(1):1-7.

2. Waris A, Khan AU, Ali M, Ali A, Baset A. COVID-19 outbreak: current scenario of Pakistan. New Microbes New Infect. 2020;35:100681.

3. Wang C, Pan R, Wan X, Tan Y, Xu L, Ho CS, Ho RC. Immediate psychological responses and associated factors during the initial stage of the 2019 coronavirus disease (COVID-19) epidemic among the general population in China. Int J Environ Res Public Health. 2020;17(5):1729.

4. Wang C, Pan R, Wan X, Tan Y, Xu L, McIntyre RS, Choo FN, Tran B, Ho R, Sharma VK, Ho C. A longitudinal study on the mental health of general population during the COVID-19 epidemic in 
China. Brain Behav Immun. 2020;87:40-8.

5. Temsah MH, Al-Sohime F, Alamro N, Al-Eyadhy A, Al-Hasan K, Jamal A, Al-Maglouth I, Aljamaan F, Al Amri M, Barry M, Al-Subaie S. The psychological impact of COVID-19 pandemic on health care workers in a MERS-CoV endemic country. J Infect Public Health. 2020;13(6):877-82.

6. Saqlain M, Munir MM, Ahmed A, Tahir AH, Kamran S. Is Pakistan prepared to tackle the coronavirus epidemic?. Drugs Ther Perspect. 2020; doi:10.1007/s40267-020-00721-1.

7. John Hopkins University. Coronavirus Resource Center. 2020. https://coronavirus.jhu.edu/region/pakistan. Accessed October 1, 2020.

8. Majeed S, Ashraf M. Psychological Impacts of Social Distancing During COVID-19 Pandemic in Adolescents of Lahore, Pakistan. Annals of King Edward Medical University. 2020;26(Special Issue):165-9.

9. Liu Y, Ning Z, Chen Y, Guo M, Liu Y, Gali NK, Sun L, Duan Y, Cai J, Westerdahl D, Liu X. Aerodynamic analysis of SARS-CoV-2 in two Wuhan hospitals. Nature. 2020;582(7813):557-60.

10. Sethi BA, Sethi A, Ali S, Aamir HS. Impact of Coronavirus disease (COVID-19) pandemic on health professionals. Pak J Med Sci. 2020;36(COVID19-S4):6-11.

11. Liu Q, Luo D, Haase JE, Guo Q, Wang XQ, Liu S, Xia L, Liu Z, Yang J, Yang BX. The experiences of health-care providers during the COVID-19 crisis in China: a qualitative study. Lancet Glob Health. 2020;8(6):e790-8.

12. Mohsin M, Syed J. The missing doctors - An analysis of educated women and female domesticity in Pakistan. Gender, Work \& Organization. 2020; doi:10.1111/gwao.12444.

13. Sun N, Wei L, Shi S, Jiao D, Song R, Ma L, Wang H, Wang C, Wang Z, You Y, Liu S. A qualitative study on the psychological experience of caregivers of COVID-19 patients. Am J Infect Control. 2020;48(6):592-8.

14. Aspers P. Empirical phenomenology: A qualitative research approach (The Cologne Seminars). IndoPacific Journal of Phenomenology. 2009;9(2):1-12.

15. Farooq MB, De Villiers C. Telephonic qualitative research interviews: When to consider them and how to do them. Meditari Accountancy Research. 2017;25(2):291-316.

16. Chew NW, Lee GK, Tan BY, Jing M, Goh Y, Ngiam NJ, et al. A multinational, multicentre study on the psychological outcomes and associated physical symptoms amongst healthcare workers during COVID-19 outbreak. Brain Behav Immun. 2020;88:559-65.

17. Lissoni B, Del Negro S, Brioschi P, Casella G, Fontana I, Bruni C, Lamiani G. Promoting resilience in the acute phase of the COVID-19 pandemic: Psychological interventions for intensive care unit (ICU) clinicians and family members. Psychol Trauma. 2020;12(S1):105-7.

18. Maunder R, Hunter J, Vincent L, Bennett J, Peladeau N, Leszcz M, Sadavoy J, Verhaeghe LM, Steinberg R, Mazzulli T. The immediate psychological and occupational impact of the 2003 SARS outbreak in a teaching hospital. CMAJ. 2003;168(10):1245-51. 
19. Duan L, Zhu G. Psychological interventions for people affected by the COVID-19 epidemic. Lancet Psychiatry. 2020;7(4):300-2.

20. Fawaz M, Samaha A. The psychosocial effects of being quarantined following exposure to COVID19: A qualitative study of Lebanese health care workers. Int J Soc Psychiatry. 2020;66(6):560-5.

21. Robert J, Piemonte N, Truten J. The reflective scribe: Encouraging critical self-reflection and professional development in pre-health education. J Med Humanit. 2018;39(4):447-54.

22. Raven J, Wurie H, Witter S. Health workers' experiences of coping with the Ebola epidemic in Sierra Leone's health system: a qualitative study. BMC Health Serv Res. 2018;18:251.

23. Chersich MF, Gray G, Fairlie L, Eichbaum Q, Mayhew S, Allwood B, et al. COVID-19 in Africa: care and protection for frontline healthcare workers. Global Health. 2020;16(1):46.

24. Aacharya RP, Shah A. Ethical dimensions of stigma and discrimination in Nepal during COVID-19 pandemic. Ethics in Med Public Health. 2020;14:100536.

25. Ali S, Noreen S, Farooq I, Bugshan A, Vohra F. Risk Assessment of Healthcare Workers at the Frontline against COVID-19. Pak J Med Sci. 2020;36(COVID19-S4):99-103.

\section{Supplementary Files}

This is a list of supplementary files associated with this preprint. Click to download.

- Additionalfile1 Interviewguide.pdf

- Additionalfile1 Interviewguide.pdf

- COREQchecklist.DOCX

- COREQchecklist.DOCX 